\title{
Research Regarding the Influence of Execution, Assembly and Functioning Errors on the Teeth Profile Modification of Spur Gear in Front Plane
}

\author{
Mircea Mera ${ }^{1,}$ and Cristina Stefana Miron-Borzan ${ }^{1^{*}}$ \\ ${ }^{1}$ Technical University of Cluj-Napoca, Manufacturing Engineering Department, 103-105 Muncii Bvd. \\ Cluj-Napoca, Romania
}

\begin{abstract}
The paper presents general aspects related to the influence of execution, assembly and functioning errors on the teeth profile modification from the spur gear in the front plane, in the case when the gear is fixed to the shaft in an asymmetrical position relative to the bearings. The numerical researches were done with FEM.
\end{abstract}

\section{General Considerations}

The spur gears have an important place among all the gears used in industry. Until today, many investigations have been presented about the production of the spur gears [1].

Every manufactured gear contains certain types and magnitudes of errors depending on the quality level imposed. Such errors often contribute to the loaded transmission error to affect the meshing dynamics of gears [2].

In the industry, gears have important application areas in the transmission of motion. Many different manufacturing methods have been tried out other than conventional methods [3]. Some researchers [4] manufactured the gear wheel by computerizing the gear tooth profile. Ozek et al. have investigated the possibility of manufacturing spur gears with CNC milling machines by the method of vertical machining [5]. Ozel [6] had investigated the cutting errors in the tooth profile of the spur gears which are manufactured by end mill according to radial cutting method in three-axis CNC milling machine. The results of his study showed that the cutting errors in the involute curve increase according to increments of module, tooth number, pressure angle and cutting angle. The impact of the operating conditions of the gears in the modern era (increasing efforts are being made to reduce the functional dimensions) as well as on the environmental protection (noise reduction and improvement of the medical-social conditions - vibrations) guided the research in the field of gearing to a higher level. The realization of these requirements is possible with the help of the modification of the gear tooth profile, both in the frontal and longitudinal planes. This allow to compensate the elastic deformations of the gear teeth, the execution and mounting errors and to locate the contact patch. Nowadays the design and manufacturing of the gears has as a base the computerised simulation of the meshing, using a Numerical Controlled Machine in manufacturing and for control a 3D Coordinate Measuring System

${ }^{*}$ Corresponding author: borzan_cristina@ymail.com 
(Machine). Numerical simulation is a very effective method for simulation various processes in many domains. A multitude of problems in engineering was solved by Fine Element Analysis [7]. Many authors used numerical simulations [7, 8, 9, 10, 11]. Nistor [8], had investigated the influence of gear geometry such as teeth number and the deformation mechanism by $3 \mathrm{D}$ finite-element analysis using FORGE software in terms of teeth forming and forming loads evolution. Based on these simulations, the experimental investigations were carried out to obtain a spur gear form with the good quality, using several billet dimensions. Berri et all [9] have introduced a developed simulator on rotational vibrations of a power transmission spur gear set with one cracked pinion tooth. The simulated outputs depicted precisely the experimental behaviours.

\section{Material and Methods}

Numerical research was carried out by applying FEM to determine the influence of execution, assembly and functioning errors on the correction depth of tooth gear (flank or correction depth) mounted asymmetrically between bearings. The spur gear is considered to be made of alloy steel, 41Mo Cr10. The cylindrical gears teeth are mainly loaded for bending and contact pressure. The load was made on the peaks of the spur gear teeth to obtain the maximum elastic deformation at bending during operation (deformation which influences the depth value of the gear tooth head modification). The Finite Element Analysis algorithm started from the gear tooth profile that was subjected to profile changes (correction of the head tooth gear). The gear tooth profile was obtained using the MAIN.CPP program. The MAIN.CPP program was developed in [10]. In this software, the 3D meshed model of the gear was made (Figure1), the limit conditions were placed, the forces were loaded and the stresses and the corresponding elastic deformations were determined. The gear model was then exported as DXF files for the ALGOR finite element analysis software. The force loading was made on the peak of the spur gear tooth as linear distributed forces over a band with a certain width due to the contact area between the flanks and they were not concentrated in points. The limitations of Algor's finite element program did not allow another representation. The elastic deformations occurring during the functioning under the load were determined by finite element analysis for each individual gear case. Execution errors, in particular those related to limit deviations for the pinion pitch and for the gear were taken from the Standards, and the assembly and execution errors were taken into account by the way the load was distributed over the tooth width of the gear.

\section{Numerical Researches with Finite Element Method}

It has been considered a cylindrical spur gear, with $\mathrm{z}=30$ teeth, module $\mathrm{m}=4 \mathrm{~mm}$, loaded with $1500 \mathrm{~N}$ linear force distributed over the teeth, asymmetrically mounted on a shaft, that sustain onto two bearings.

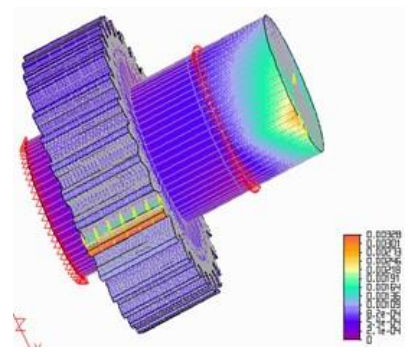

Fig. 1. The elastically deformed gear, asymmetrically mounted between bearings and loaded with linear distributed forces. 
There were considered the following situations often encountered in practice classified by the ratio $b_{c a l} b$, (Figure 2) where: $b_{c a l}$ represents the calculation teeth width and $b$ the gear tooth width, in [mm].

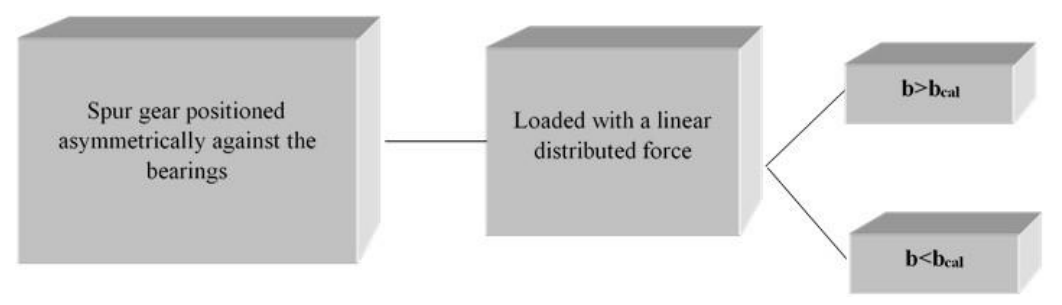

Fig. 2. The analysed algorithm.

In the case of the elastically deformed gear, asymmetrically fixed between bearings and loaded with linearly distributed forces, when $b_{c a l}<b$ (the gear is slightly loaded and / or the total deviation of the tooth direction has a high value), the values of the elastic deformations of the gear teeth are shown in Table 1, and the model gear- shaft, elastically deformed in Figure 3.

Table 1. The values for the elastic deformation of the gear tooth in the case of loading with linearly distributed forces, $b_{c a l}<b$.

\begin{tabular}{|c|c|}
\hline $\begin{array}{c}\text { Coordinates of points in the } \\
\text { longitudinal plane of the } \\
\text { tooth, }[\mathrm{mm}]\end{array}$ & $\begin{array}{c}\text { Elastic deformation of the gear } \\
\text { according to the applied force } \\
\text { direction, }[\mu \mathrm{m}]\end{array}$ \\
\hline 0 & 5,606 \\
\hline 6,66 & 4,671 \\
\hline 13,32 & 4,045 \\
\hline 19,98 & 3,296 \\
\hline 26.24 & 2,567 \\
\hline 33,3 & 1,922 \\
\hline 40 & 1,49 \\
\hline
\end{tabular}

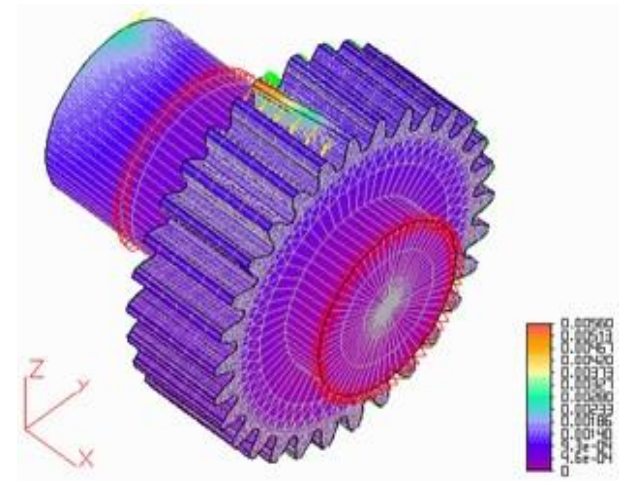

Fig. 3. The elastically deformed gear, asymmetrically fixed between bearings and loaded with linearly distributed forces, $b_{c a l}<b$.

Analysing the values from Table 1, it can be observed that for the case of asymmetric position of the gear to the bearings, the maximum value was $5,606 \mu \mathrm{m}$, on the end portion of the gear from the side where is applied the force that creates the torque moment.

The correction depth of the profile $(\Delta \mathrm{a})$, determined with relation 1 [10], is 22,6 $\mu \mathrm{m}$.

$$
\Delta_{a}=f_{\Sigma_{P_{b}}}+\delta_{e}
$$


where: $\bullet \delta_{\mathrm{e}}$. represents the size of the elastic deformations of the gear teeth under load;

- $\mathrm{f}_{\Sigma \mathrm{pb}}$ is the mean square deviation of the limit deviations of the pitches of the pinion and gear; it is calculated with:

$$
f_{\Sigma_{p b}}=\sqrt{f_{p_{b 1}}^{2}+f_{p_{b 2}}^{2}}
$$

Table 2. The values for the elastic deformation of the gear tooth in the case of loading with linearly distributed loads, $b_{c a l}>b$.

\begin{tabular}{|c|c|}
\hline $\begin{array}{c}\text { Coordinates of points in the } \\
\text { longitudinal plane of the tooth, }[\mathrm{mm}]\end{array}$ & $\begin{array}{c}\text { Elastic deformation of the gear according to } \\
\text { the applied force direction, }[\mu \mathrm{m}]\end{array}$ \\
\hline 0 & 4,411 \\
\hline 6,66 & 4,243 \\
\hline 13,32 & 3,786 \\
\hline 19,98 & 3,234 \\
\hline 26.24 & 2,714 \\
\hline 33,3 & 2,253 \\
\hline 40 & 2,07 \\
\hline
\end{tabular}

For the $b_{c a l}>b$ case encountered when the gear is heavily loaded and/or the total deviation of the tooth direction has a low value, the gear-shaft model (designed for the asymmetric position of the gear relative to the bearings) is shown in a elastic deformed state, in Figure 4.

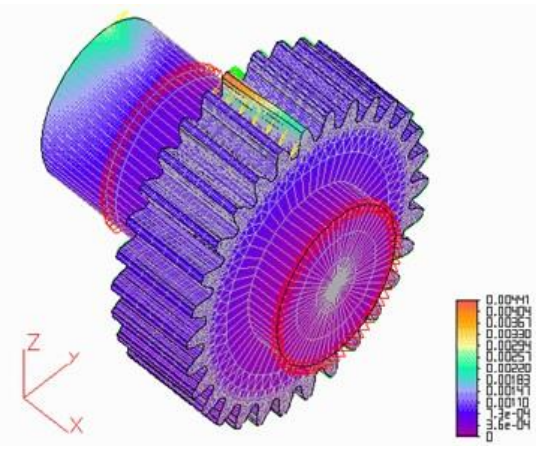

Fig. 4. The elastically deformed gear, asymmetrically fixed between bearings and loaded with linearly distributed forces, $b_{c a l}>b$.

The maximum tooth deflection was observed on the end portion of the gear' tooth, from the area where the torque force was applied and it had the value of 4,411 $\mu \mathrm{m}$. Thus, the recommended depth of head profile correction for this variant is $21,4 \mu \mathrm{m}$, calculated with relation (1).

Analysing these values, it results that the elastic deformations for the gears teeth in case of loading with linearly distributed forces are lower for $b_{c a l}>b$. It means that the elastic deformations during operating time, in the case of the direction errors of the gear tooth (due to the executions or mounting errors), are lower and/ or the gear is strongly loaded.

\subsection{The Load Distribution Calculation on the Tooth Width}

The load distribution on the tooth width, when the force has a linear distribution is illustrated in figure 5 and the required formulas for calculate the distribution are presented in the following $(3)-(9)$ relations. 
The force linear evolution of the $b$ width of the gear tooth can be described as a linear function, such as:

$$
p(x)=m x+n
$$

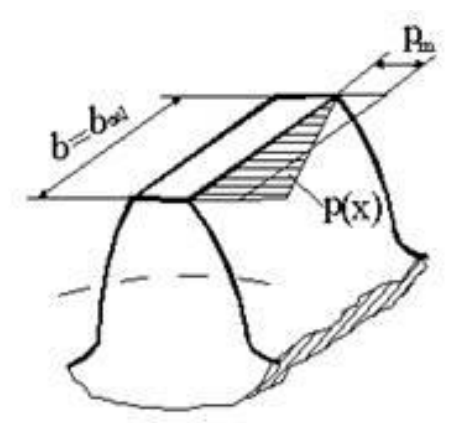

Fig. 5. The forces linear distribution, for the case $b=b_{\text {cal }}$.

By imposing the limit conditions, it results:

$$
\begin{aligned}
& p(0)=p_{\text {max }} \Rightarrow n=p_{\max } \\
& p(b)=0 \Rightarrow m b+n=0 \Rightarrow m=-\frac{p_{\max }}{b}
\end{aligned}
$$

and equation (3) becomes:

$$
p(x)=p_{\max }\left(1-\frac{x}{b}\right)
$$

The F force, which is applied on the tooth, can be calculated by:

$$
F=\int_{0}^{b} p(x) d x=\int_{0}^{b} p_{\max }\left(1-\frac{x}{b}\right) d x=p_{\max } \frac{b}{2}
$$

On the b width of the tooth, a number (n) of knocks is established, so (n-1) subintervals are obtained. The force corresponding to each subinterval can be calculated:

$$
F_{\text {int }}=\frac{2 F}{b}\left(x_{1}-x_{0}\right)\left(1-\frac{x_{1}+x_{0}}{2 b}\right)
$$

The following recurrence formula was established:

$$
F_{k}=\frac{F\{2(n-1)-[k+(k-1)]\}}{(n-1)^{2}}
$$

where $\mathrm{k}$ represents the subinterval numbers and $\mathrm{F}_{\mathrm{k}}$ is the linear variable force on $\mathrm{k}$ subinterval.

If is considered the case when $b>b_{c a l}$ or $b<b_{c a l}$ respectively, the linear variable force on every subinterval is calculated as follows:

$$
F_{k}=\frac{F\{2 i-[k+(k-1)]\}}{i^{2}}
$$

where: $b_{c a l}=i b /(n-1)$ and $i$ represents the number of subintervals on the tooth width.

The table 3 presents the linear distributed forces, calculated with the above presented formulas, applied into the knocks of the finite element network, within the FEM analyses performed for the considered cases. 
Table 3. The values for the elastic deformation of the gear tooth in the case of loading with linearly distributed loads, $b_{\text {cal }}>b$.

\begin{tabular}{|c|c|c|c|}
\hline \multirow{2}{*}{$\begin{array}{c}\text { Node number in the finite } \\
\text { elements network in which } \\
\text { force is applied }\end{array}$} & \multicolumn{3}{|c|}{$\begin{array}{c}\text { The values of the linear force [N], } \\
\text { distributed in the network nodes for the cases: }\end{array}$} \\
\cline { 2 - 4 } & $\mathrm{b}=\mathrm{b}_{\text {cal }}$ & $\mathrm{b}>\mathrm{b}_{\text {cal }}$ & $\mathrm{b}_{2}<\mathrm{b}_{\text {cal }}$ \\
\cline { 2 - 4 } & \multicolumn{2}{|c|}{ The number of the calculation subinterval, $i$} \\
\cline { 2 - 4 } & $i=6$ & 270 & $i=7$ \\
\hline 1 & 229,165 & 480 & 199 \\
\hline 2 & 416,665 & 360 & 367,34 \\
\hline 3 & 333,33 & 240 & 244,9 \\
\hline 4 & 249,995 & 120 & 183 \\
\hline 5 & 166,665 & 30 & 122,45 \\
\hline 6 & 83,33 & & 61,22 \\
\hline 7 & 20,83 & & 15,3 \\
\hline 8 & & & \\
\hline
\end{tabular}

\section{Conclusions}

The paper presents a method of determining the value of the modification parameters of the teeth profile for a cylindrical spur gear in the frontal plane. Finite element analysis was used to determine the elastic deformations during operating. The spur gear was considered to be asymmetrically positioned between the bearings, a case commonly encountered in practice. Execution and assembly errors have been highlighted by the force loading distribution on the teeth width of the spur gear (distributed linear forces).

Future researches will be orientated to perform studies which should lead to establish the following things: the influence of the tooth width load distribution on parameters value for gear teeth profile modification; the influence of the gear with respect to the roller bearings, on parameters value for gear teeth profile modification.

This work was supported by a grant of the Romanian National Authority for Scientific Research and Innovation, CNCS/CCCDI-UEFISCDI, project number PN-III-P2-2.1-BG-2016-0216, within PNCDI III.

\section{References}

1. C. Özel, Int J. Adv Manuf Tech, 54, 1-4 (2011)

2. M.Inalpolat, M. Handschuh, A. Kahraman, Int. Gear Conf. Lyon, Gear Techn, 64 (2015)

3. M. Uzun, Adv Manuf Tech, 77, 5-8 (2015)

4. C.B. Tsay, W.Y. Liu, C. Yi-Chen, J Mater Process Technol 104, 271 (2000)

5. C. Ozek, C. Ozel, J Mach Eng, 512, 43 (2002)

6. C. Özel, Int J. Adv Manuf Tech, 59, 1-4, (2012)

7. P. Bella, P.Buček, M. Ridzoň, M. Mojžiš, L. Parilák, Key Eng. Mater., 716708 (2016)

8. L. Nistor, A. Neag, I.Marian, D.Frunza, J. Manuf. Sci. Eng, 138, 12 (2016)

9. S.M. Berri, J. M. Klosner, Education ASME Turbo Expo 2000: Power for Land, Sea, and Air, Germany, 4, (2000)

10. M. Mera, Research on the development of high-performance cylindrical gears, UTCN (2001)

11. V. A.Ceclan, N.Bâlc, A. V. Miron, C. Borzan, A. Popan, AJME, 9, 3 (2011)

12. Weck, M. Numerisch gesteuertes Abrichten von Profilschleifscheiben, Industrie Anzeiger, 54, 12 (1981)

13. M. Mera, C. Gyenge, S. Comşa, O. Mera, 6th. Int. DAAAM Symposium, Krakow, 227 (1995)

14. M. Mera, C. Gyenge, S. Comşa, Int. DAAAM Symposium Cluj-Napoca (1998)

15. Suhoenkov N. Modification of the evolving cylindrical spur gears, (Tehnica, Kiev, 1992) 